\title{
Fetal and Placental Responses to Artificially Induced Hyperthermia in Rats
}

\author{
K. L. ARORA, B. J. COHEN AND A. R. BEAUDOIN \\ Unit for Laboratory Animal Medicine and Department of Anatomy, University of \\ Michigan Medical School, Ann Arbor, Michigan 48109
}

\begin{abstract}
Pregnant rats were utilized to study the effect of maternal hyperthermia on fetal development. Eight groups of six to eight rats were exposed to ambient temperatures of $43-44^{\circ} \mathrm{C}$ at various stages of pregnancy. All rats were killed on day 20 of gestation. Edema, microencephaly and microphthalmia followed heat treatment on day 4,6 , or 8 and skeletal defects occurred on day 10 of gestation. Apparently heat stress of dams after day 14 of gestation had little or no effect on embryos. Most placentas from day 6-10 treatment groups were significantly heavier than control and exhibited extensive thickening and necrosis of decidua basalis. Our results suggest that the rat is a useful model for investigating maternal hyperthermia as a possible cause of human placentophathies and fetal retardation.
\end{abstract}

A variety of factors contribute to the incidence of congenital malformations in animals and in man. Genetic mutation, irradiation, infections, drugs and nutritional deficiencies are among the well established inciting causes. Evidence implicating hyperthermia as a teratogenic agent is now overwhelming. Studies with rodents have shown that both the duration and level of hyperthermia affected maternal survival as well as the incidence of fetal malformations; the disturbances of central nervous system were by far the most common defects (Edwards, '69; Kilham and Ferm, '76). Earlier, Skreb and Frank ('63) reported various types of defects in fetal rats following the immersion of exteriorized pregnant uterine horns in warm saline. However, the mechanism by which heat stress produces embryopathies when associated with elevated maternal temperature is less well understood. Edwards et al. ('74) revealed that subjecting of pregnant animals to high incubation temperatures caused clumping of chromosomes, inhibition of mitotic activity and later death of neuro-ectoderm cells in the fetus. Presumably, similar cellular changes in response to heat stress would be expected to cause developmental anomalies in other embryonic structures as well.

In human subjects, fever is a possible, but unproven cause of spontaneous fetal abortions, retardations and abnormalities. The dif- ficulty in obtaining clinical or experimental evidence on the fetal or placental effect of maternal hyperthermia resulting from infections or exposure to higher than normal environmental temperatures in human subjects is obvious. The significant problems involved can best be examined in animal models. Experiments on the influence of maternal hyperthermia on fetal rat development in utero are the subject of this report. This study also includes observations on hyperthermia-induced alterations in decidua basalis of placentas.

\section{MATERIALS AND METHODS Animals}

Outbred nulliparous Spartan female rats (Spb: (SD)BR) Spartan Research Animals, Haslett, Michigan, weighing 250-275 g were housed in groups of six in stainless steel cages under a lighting schedule of 14 hours light and 10 hours of complete darkness and given a commercial pelleted laboratory ration (Ralston Purina Company, St. Louis, Missouri) and tap water ad libitum. After seven days of acclimatization, rats in proestrus were caged with males of the same stock overnight.. Mating was confirmed by detection of vaginal plug or spermatozoa in the vaginal smear the following morning (day 0 of gestation). Mated females then were separated from the males

\footnotetext{
Received Nov. 5, '77. Accepted Oct. 18, '78.
} 
and assigned randomly to treatment or control groups.

\section{Application of heat}

Pregnant rats in the treatment groups were heat stressed on one of eight days during gestation (day 4, 6, 8, 10,12,14,16 or 18) for 90 minutes in the morning and 45 minutes in the afternoon in an electrical microbiological incubator (Blue M Electric Company, Blue Island, Illinois) set at $43-44^{\circ} \mathrm{C}$. Food and water were withheld during the heat treatment, during the interval between the treatments, and for about one hour following removal of the rats from the incubator. The rats were weighed and rectal temperature was measured immediately before and after each heating period. The temperature gradient between fetus and the mother during the heating period was not determined. After the heat stress, the rats were returned to their cages and were kept at room temperature until killed on day 20 of gestation. Control females were treated identically as the heat stressed females, except that they were weighed every other day and were not heat stressed.

\section{Examination of reproductive tract and fetuses}

On day 20 of gestation, the rats were

TABLE

Effect of hyperthermia on maternal weight gain, implantations and resorptions

\begin{tabular}{|c|c|c|c|c|c|}
\hline $\begin{array}{l}\text { Day of } \\
\text { pregnancy } \\
\text { when heat } \\
\text { applied }\end{array}$ & $\begin{array}{l}\text { No. of } \\
\text { females }\end{array}$ & $\begin{array}{c}\text { Range of } \\
\text { post-stressing } \\
\text { temperatures } \\
\left({ }^{\circ} \mathrm{C}\right)^{\mathrm{a}}\end{array}$ & $\begin{array}{c}\text { Mean weight } \\
\text { gained during } \\
\text { pregnancy } \\
(\mathrm{g})\end{array}$ & $\begin{array}{l}\text { Implantations } \\
\text { (\% of CL number) }\end{array}$ & $\begin{array}{l}\text { Resorptions } \\
\text { (\% of total } \\
\text { implantations) }\end{array}$ \\
\hline 4 & 6 & $40.8-41.8$ & $120.8^{*}$ & 81 & $12.3^{*}$ \\
\hline 6 & 7 & $40.6-41.8$ & $121.4^{*}$ & 93 & 5.9 \\
\hline 8 & 7 & 41.3.41.5 & $124.3^{*}$ & 93 & 3.4 \\
\hline 10 & 7 & $41.0-42.5^{b}$ & $124.0^{*}$ & 91 & 2.1 \\
\hline 12 & 8 & $40.2-41.5$ & 133.3 & 90 & 0.9 \\
\hline 14 & 7 & $41.4-42.7^{b}$ & 132.8 & 93 & 2.8 \\
\hline 16 & 7 & $40.3-41.5$ & 135.4 & 90 & 1.4 \\
\hline 18 & 6 & $40.5-41.2$ & 133.0 & 91 & 2.3 \\
\hline $\begin{array}{l}\text { Control } \\
\text { (day 20) }\end{array}$ & 8 & $38.0-38.3$ & 134.8 & 93 & 1.9 \\
\hline
\end{tabular}

* Significant]y different from control, $P<0.01$.

a For heating procedures see MATERIALS AND METHODS.

$\mathrm{b}$ In one rat of day 10 group and in two rats of day 12 group the rectal temperatures rose at $42.0^{\circ} \mathrm{C}$ or above during the heat treatment.

TABLE 2

Effect of hyperthermia on fetal weights and developmental aberrations

\begin{tabular}{|c|c|c|c|c|c|c|}
\hline \multirow{2}{*}{$\begin{array}{c}\text { Day of } \\
\text { pregnancy } \\
\text { when heat } \\
\text { applied }\end{array}$} & \multirow{2}{*}{$\begin{array}{l}\text { No. of } \\
\text { litters : }\end{array}$} & \multirow{2}{*}{$\begin{array}{c}\text { Litter size } \\
\text { Mean } \pm S D\end{array}$} & \multirow{2}{*}{$\begin{array}{l}\text { Fetal wt (g) } \\
\text { Mean } \pm \mathbf{S D}\end{array}$} & \multirow{2}{*}{$\begin{array}{c}\text { Placental wt }(\mathrm{g}) \\
\text { Mean } \pm \mathrm{SD}\end{array}$} & \multicolumn{2}{|r|}{$\begin{array}{l}\text { Gross fetal } \\
\text { aberrations }\end{array}$} \\
\hline & & & & & $\%$ & Type (n) \\
\hline 4 & 6 & $10.1 \pm 0.8^{2}$ & $3.31 \pm 0.41^{2}$ & $0.52 \pm 0.06$ & 6.7 & $\begin{array}{l}\text { edema (3) } \\
\text { microencephaly (1) }\end{array}$ \\
\hline 6 & 7 & $12.6 \pm 0.9$ & $3.42 \pm 0.28^{2}$ & $0.63 \pm 0.05^{2}$ & 5.6 & $\begin{array}{l}\text { edema (2) } \\
\text { microencephaly (3) }\end{array}$ \\
\hline 8 & 7 & $12.3 \pm 1.4$ & $3.64 \pm 0.42^{2}$ & $0.62 \pm 0.09^{2}$ & 2.4 & $\begin{array}{l}\text { microencephaly (1) } \\
\text { microphthalmia (1) }\end{array}$ \\
\hline 10 & 7 & $12.8 \pm 2.8$ & $3.90 \pm 1.32$ & $0.63 \pm 0.08^{2}$ & 0 & skeletal 3 \\
\hline 12 & 8 & $11.4 \pm 0.9$ & $3.86 \pm 0.46$ & $0.54 \pm 0.05$ & 0 & nil \\
\hline 14 & 7 & $11.3 \pm 1.8$ & $3.65 \pm 1.42$ & $0.53 \pm 0.06$ & 0 & nil \\
\hline 16 & 7 & $13.0 \pm 0.6$ & $4.13 \pm 0.38$ & $0.55 \pm 0.05$ & 0 & nil \\
\hline 18 & 6 & $12.6 \pm 1.3$ & $4.18 \pm 0.46$ & $0.54 \pm 0.08$ & 0 & nil \\
\hline $\begin{array}{c}\text { Control } \\
\text { (day 20) }\end{array}$ & 8 & $13.1 \pm 0.7$ & $4.10 \pm 0.32$ & $0.55 \pm 0.05$ & 0 & nil \\
\hline
\end{tabular}

' Number of litters is the same as the number of females in table 1.

${ }^{2}$ Significantly different from control, $P<0.05$ (Student's $t$ test).

${ }^{3}$ See the results under Developmental aberrations. 


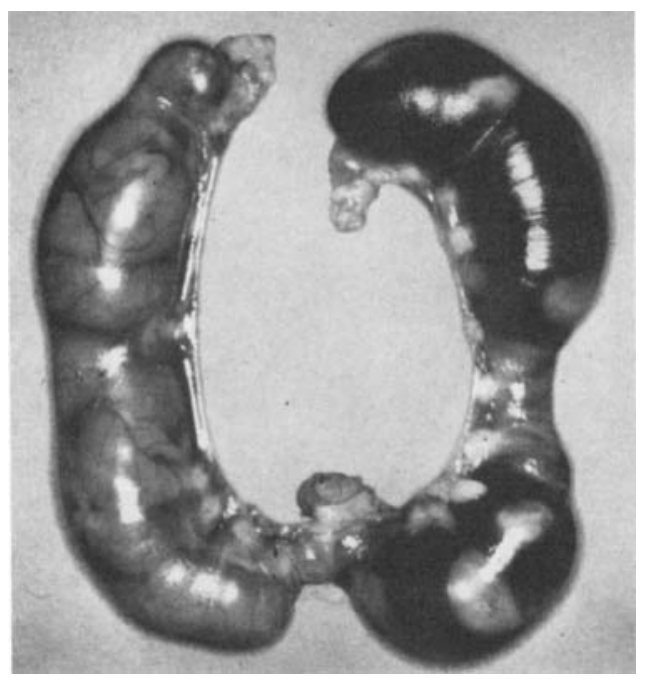

Fig. 1 Intra-uterine hemorrhage in the right horn; the dam was heat-stressed on day 8 of pregnancy.

anesthetized with methoxyflurane and exsanguinated from the abdominal aorta. The uterine horns and ovaries were removed; and the corpora lutea, dead and living fetuses, and resorption sites were counted. Fetuses and their placentas were recovered and weighed individually. Half of the living fetuses from each litter were fixed in Bouin's fluid and subsequently examined under low magnification for external and internal defects. The remaining fetuses were fixed in $95 \%$ ethanol or $10 \%$ buffered formalin and subsequently stained with alizarin red or methylene blue for identification of bone and cartilage. Placentas were fixed in $10 \%$ buffered formalin, embedded in paraffin, sectioned at $5 \mu \mathrm{m}$ and stained with hematoxylin and eosin.

\section{RESULTS}

\section{Maternal weight gain during pregnancy}

Table 1 summarizes data on maternal weight gain during pregnancy in relation to the elevation of rectal temperature. Heat treatment significantly suppressed maternal weight gain during pregnancy when given during earlier stages of pregnancy. The effect was most severe following treatment at days 4-10 and negligible thereafter (table 1). However, subsequent analysis of the data indicated that one rat of the day 10 group and two rats of the day 14 group, whose rectal temperatures had risen above $42^{\circ} \mathrm{C}$ during heat treatment, gained less weight than the other group-mates whose rectal temperature had not risen above $41.8^{\circ} \mathrm{C}$.

\section{Implantations, resorptions, litter size and fetal growth}

Heat treatment decreased embryo survival when applied at day 4 of pregnancy, as reflected in a reduction in implantations and an increase in resorptions (table 1). Reduction in litter size was observed in day 4 treatment group only (table 2). Heat did not affect implantation, resorption, or litter size when applied after day 4 of pregnancy. Other sequelae to heat treatment on day 4 were crowding and uneven spacing of implantations in the uterine horns of some rats. One rat of each of the day 6 and 8 groups exhibited intra-uterine haemorrhage (fig. 1) in one of the gravid horns and the fetuses contained in them were dead.

Mean fetal weights in day 4-14 treatment

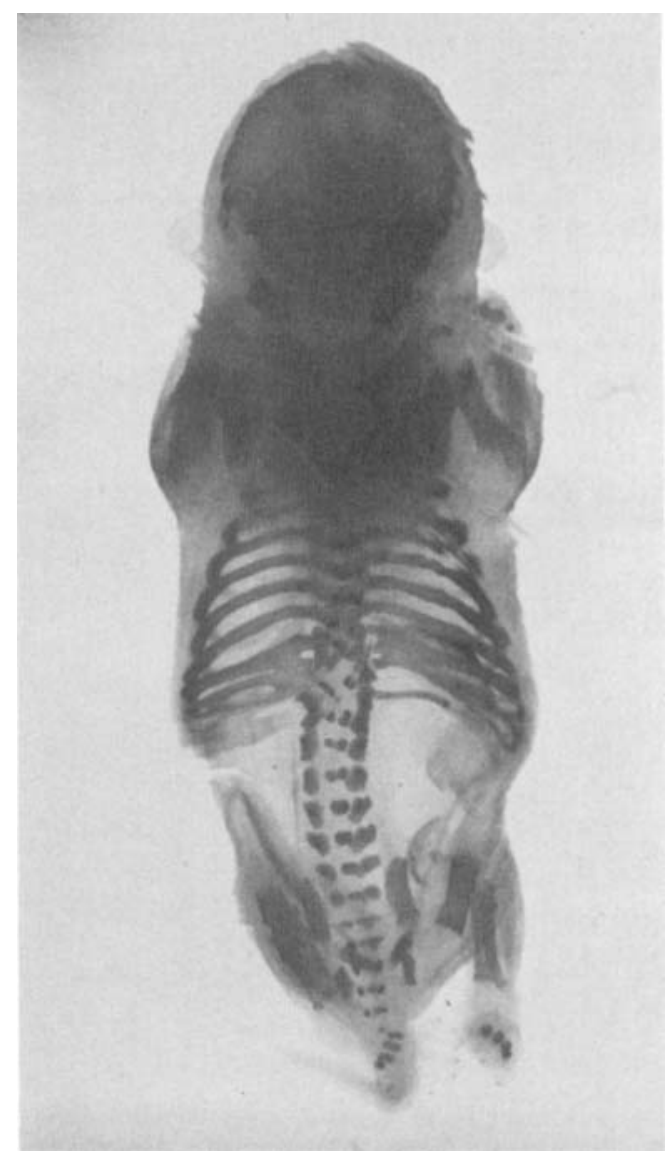

Fig. 2 Fused ribs in a day 20 fetus; the dam was heatstressed on day 10 of pregnancy. Alizarin red staining. 


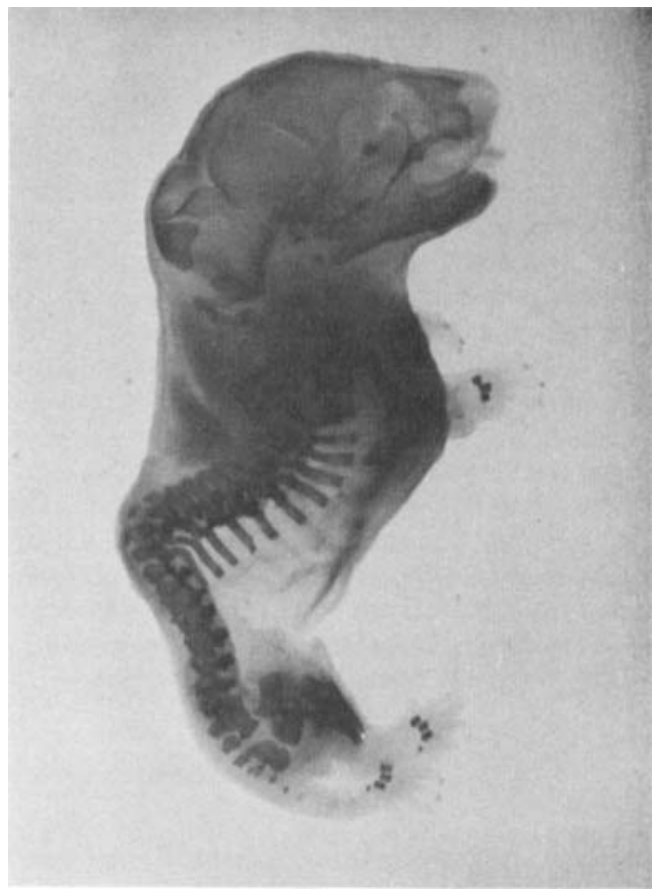

Fig. 3 Kyphosis in a day 20 fetus; the dam was heat stressed on day 10 of pregnancy. Alizarin red staining.

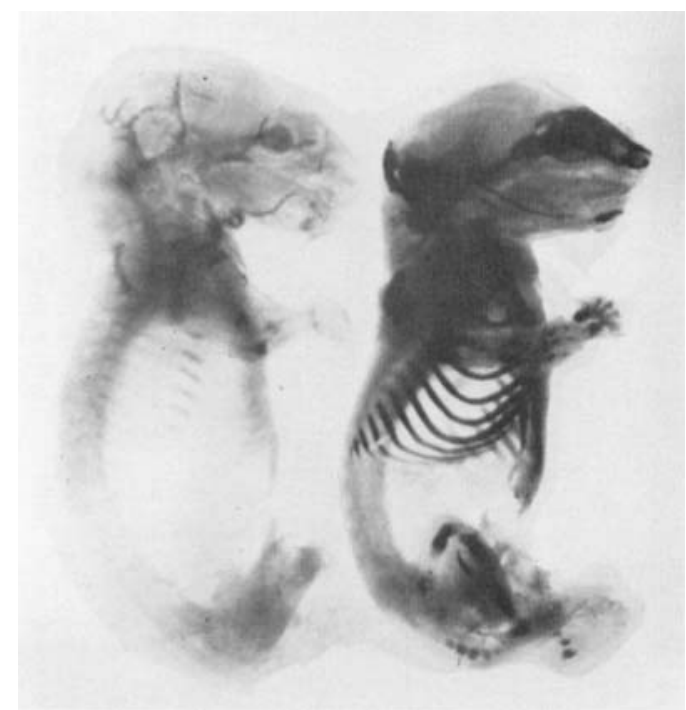

Fig. 4 Cartilagenous skeletons of day 20 fetuses; control (left) and day 6 heat-stressed (right) stained with methylene blue. Note intense staining due to the persistence of cartilage in the heat-stressed rat.

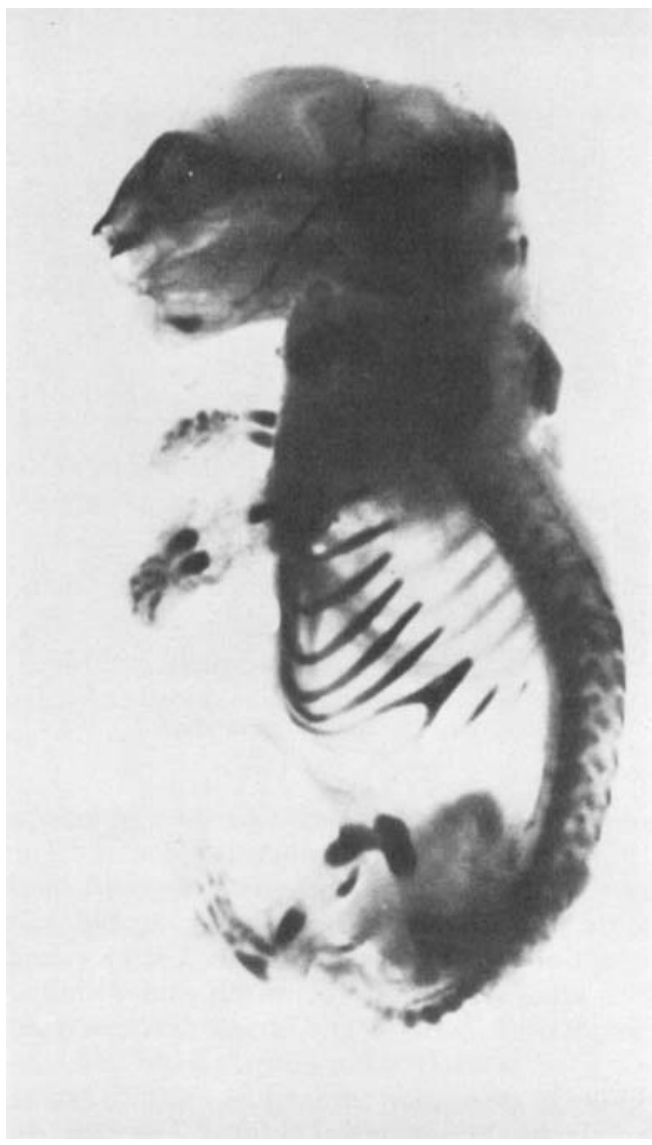

Fig. 5 Bifurcation of the chondral portion of the rib in a day 20 fetus; the dam was heat-stressed on day 10 of gestation. Methylene blue staining.

groups were relatively lower than controls; thereafter, heat treatment failed to affect fetal weight (table 2).

\section{Developmental aberrations}

Gross developmental aberrations were limited to the early treatment groups; the incidence was $4 / 60(6.7 \%), 5 / 90(5.6 \%)$ and $2 / 84$ $(2.4 \%)$ in day 4,6 and 8 treatment groups, respectively. Facial edema and microencephaly were the principal aberrations. One fetus with microphthalmia was detected in the day 8 treatment group (table 2). No gross anomalies were detected in the groups treated at the later stages of pregnancy. Examination of 812 alizarin red stained specimens from each of the treatment and control groups revealed skeletal anomalies only in the day 10 treatment group (table 2). Three of the 12 fetuses 


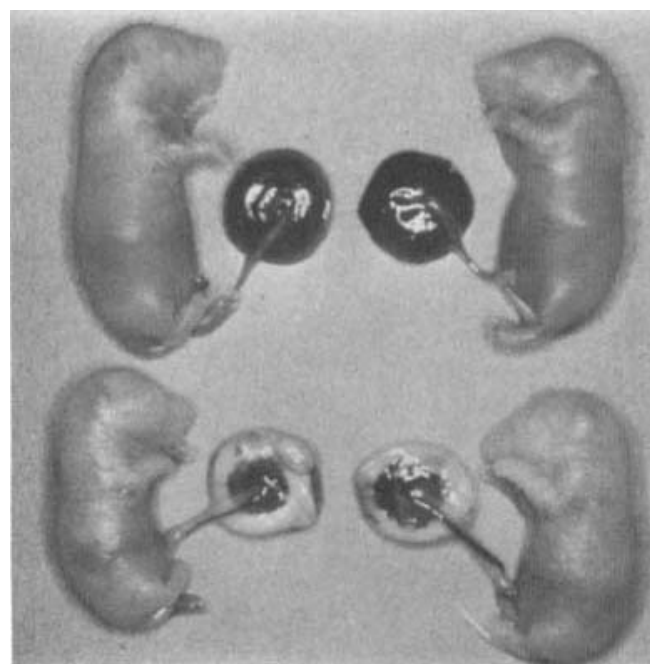

Fig. 6 Placentas from control (top) and day 8 heat stressed (bottom) dams. The placentas from the heat stressed dam are necrotic.

examined were defective; rib fusion (fig. 2), kyphosis (fig. 3) or bending and abnormal ossification of ribs was detected. Furthermore, fetuses treated at days 4-10 exhibited extreme variation in the number of sternal, phalangeal and caudal ossification centers as compared to controls, thus reflecting a general retardation in skeletal maturation. This was confirmed by examining cartilage stained specimens; methylene blue staining indicated the prolonged persistence of cartilage in the heat stressed fetuses (fig. 4). One case of bifurcation of the chondral portion of the rib was detected in the day 10 treatment group (fig. 5). Cartilagenous anomalies were not detected in any of the other groups. No skeletal anomalies were detected in control fetuses.

\section{Placental growth}

The effect on placental weight of heat treatment on days 6-10 of gestation was variable; the placentas usually were larger and heavier than control (table 2). Furthermore, the maternal and fetal surfaces of most of these placentas were necrotic (fig. 6). Histological examination of these placentas revealed thickening of the decidua basalis accompanied by extensive suppuration and necrosis (fig. 7 and 8) when compared with control (fig. 9). Calcific foci were also seen commonly in necrotic areas. Pyknosis and karyorrhexis were observed in the giant cells of the basal zone, particularly along the junction with the decidua basalis with a frequency much greater than in controls.

\section{DISCUSSION}

Our results demonstrate that thermal insult applied through maternal hyperthermia during days 6-10 of gestation was invariably associated with thicker, heavier placentas, and degeneration of the decidua basalis of the placentas. Whether or not these pathological changes would impair fetal circulation is difficult to ascertain from these observations, however, the majority of the fetuses associated with these placentas were undoubtedly smaller than control (table 2). Impaired uterine circulation is expected to reduce blood flow to the fetuses and thereby impair nutritional and other important placental functions (Nelsen and Srebnik, '70; Bruce, '72; Csapo and Weist, '73). Placental alterations as observed in this study and their significance need further exploration.

Hyperthermia induced embryonic mortality was limited primarily to the preimplantation stage (day 4). Once the embryos were implanted, at about day 6 of pregnancy, their viability was little affected by the heat stress. However, subsequent fetal growth was indeed affected in day 4-14 treatment groups, as indicated by the presence of fetuses with lower weights and developmental aberrations. Furthermore, an interesting relationship between the level of maternal hyperthermia and fetal retardation was evident from our data; litters from dams whose post-heating rectal temperature rose to $42^{\circ} \mathrm{C}$ or above weighed less than did litters whose dam's temperature remained lower (data not shown in the tables).

Our studies demonstrate that a rise in maternal temperature to $42^{\circ} \mathrm{C}$ or above is critical in rats and fetal aberrations could occur at elevated maternal temperatures of 2.5$3.5^{\circ} \mathrm{C}$ than the $4.9^{\circ} \mathrm{C}$ or above reported by Edwards ('68). Developmental anomalies also have been shown to occur at $2.8-3.5^{\circ} \mathrm{C}$ above preheating temperatures in mice (Lecyk, '69) and $3.5-4.0^{\circ} \mathrm{C}$ in cotton-eared marmosets (Poswillo et al., '74) and the bonnet monkey (Hendrickx and Stone, '76) and $3-4^{\circ} \mathrm{C}$ in hamsters (Kilham and Ferm, '76). Microencephaly was the single most common developmental aberration detected in fetuses exposed to thermal insult at days 4-8 of gestation. Edwards ('69) described microencephaly in guinea pig embryos exposed to hyperthermia between days 18-25 of gestation. The skeletal anom- 


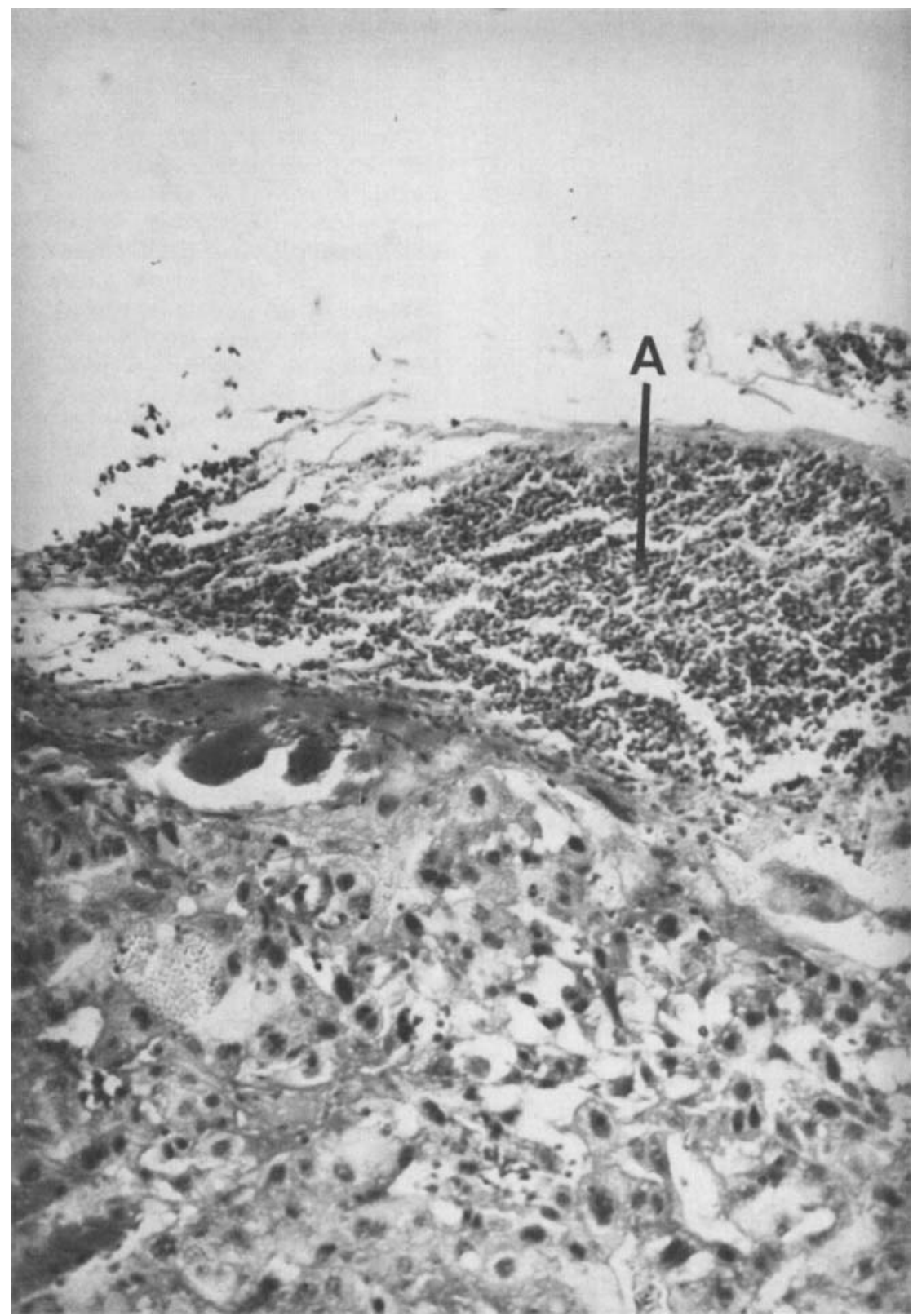

Fig. 7 Section of a placenta from day 8 heat-stressed dam (fig. 6). Inflammatory and degenerative cells (A) are present in the decidua basilis $(400 \times)$. Hematoxylin and eosin staining.

alies in our study were limited exclusively to day 10 of gestation, thus suggesting that embryonic mesenchyme at this stage of morphogenesis is vulnerable to heat stress or hypoxia. An overall delay in skeletal maturation in fetuses stressed at days 4-10 of gestation, how- ever, appear to be in conformity with the general depression in fetal growth. Heat stress apparently had little or no effect when applied after day 14 of gestation.

The mechanism of action of heat as a teratogen in mammalian species is not fully under- 


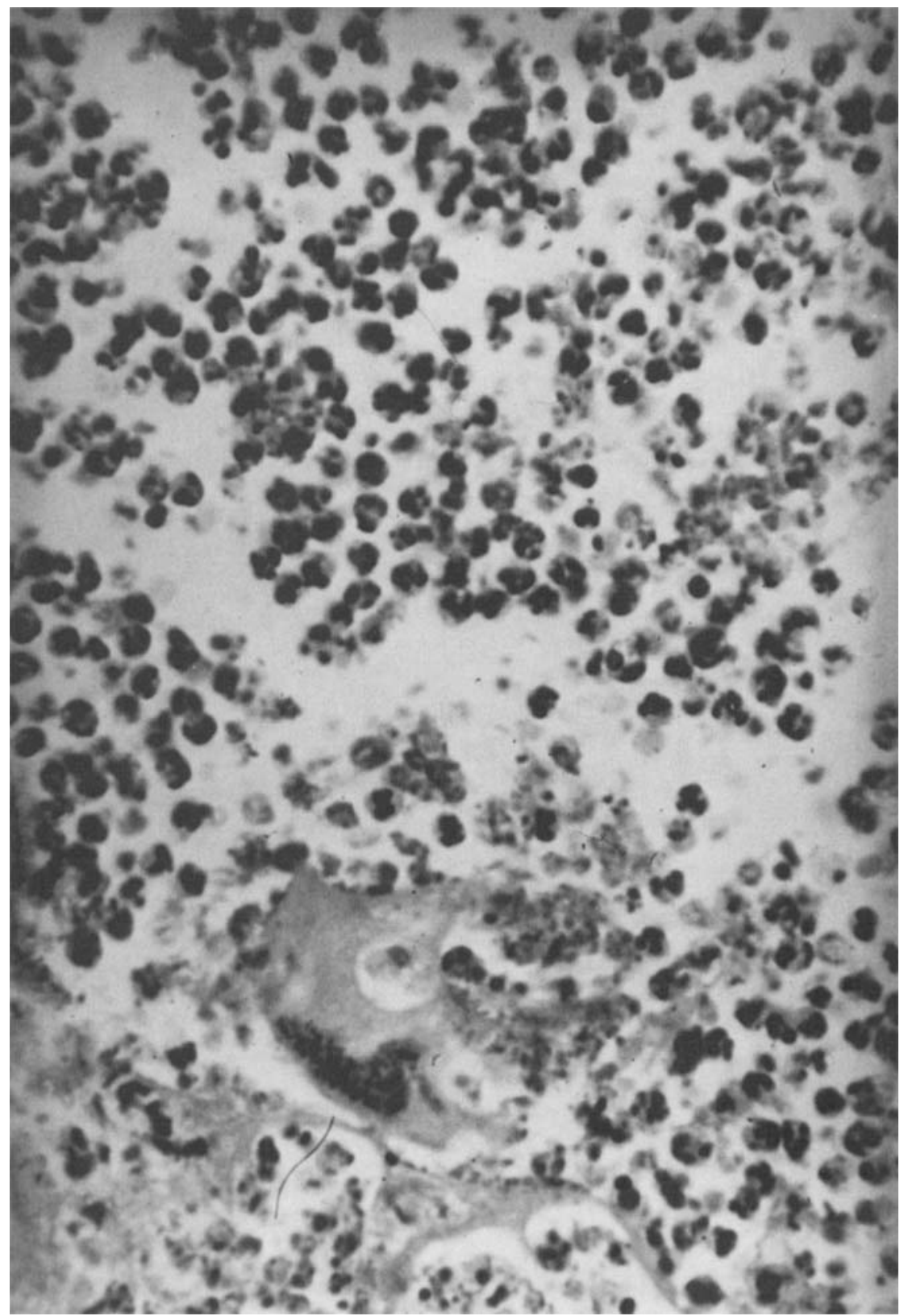

Fig. 8 Portion of decidua basalis shown in figure 7 at higher magnification $(750 \times)$. Note the presence of inflammatory cells.

stood particularly when applied through maternal hyperthermia. A direct damaging effect of heat through maternal hyperthermia was suggested in the findings of Edwards ('69) in guinea pigs where the total wet weight of the brain was reduced in direct proportion to the increase in maternal temperature. This may have resulted from fetal cellular deaths and inhibition of mitotic activity which were reported following the application of maternal hyperthermia in the same species at day 21 of gestation (Edwards et al., '74). This phenome- 


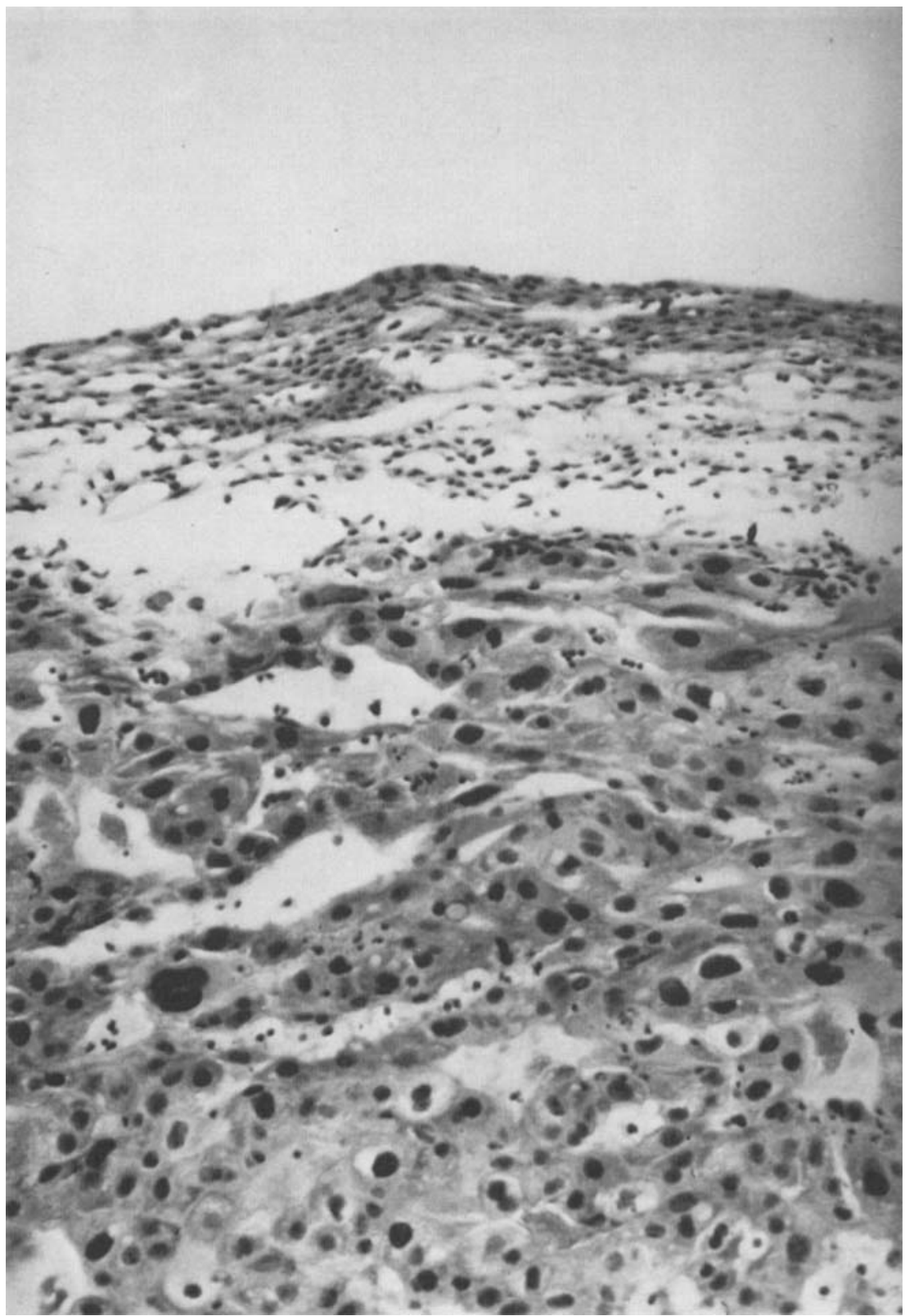

Fig. 9 Section of a placenta from control dam. Note the absence of inflammatory cells in the decidua basalis $(400 x)$.

non could also explain reduction in fetal weights in our studies particularly in those whose maternal body temperature rose to $42^{\circ} \mathrm{C}$ and above. A damaging effect of direct heat on early embryogenesis has been reported in in vitro studies with the rat (Cock- roft and New, '75), toad (Hasegawa, '55), rabbit (Lund, '69) and the chicken (Nielsen, '69).

In addition to the direct effect of heat the results of several other investigators imply a possible indirect effect of thermal stress through changes in maternal metabolism 
(Geber, '62; Collins and Weiner, '68; Morishima et al., '75). The involvement of placenta in this complex of factors could not be ruled out. Bruce ('76) showed that uterine ischemia even for a short period could markedly reduce fetal weights; the effect was greater at higher abdominal temperatures. A marked fetal retardation in the rhesus monkey followed placental insufficiencies induced experimentally by Myers et al. ('71).

Thus, it is tempting to conclude that direct thermal heat could act synergistically with reduced blood supply or hypoxia and bring about fetal retardation and aberrations during the earlier stages of pregnancy. Excessive dehydration accompanying temperature elevation due to failing thermoregulation (Hainsworth, '68) would undoubtedly increase damage to the fetuses.

Fever has not been ruled out as a cause of human abortion, embryonic retardation, or malformation (Edwards, '72; Lewin, '73; Morishima et al., '75). It is possible that hyperthermia associated with higher than normal environmental temperatures or infections could have important implications in human subjects. Our studies indicate that the rat placenta is sensitive to thermal stress and therefore could be a useful model for investigating maternal hyperthermia as a cause of placentophathies and fetal aberrations.

\section{ACKNOWLEDGMENTS}

This study was supported in part by training grant RR05001 and by RR00200 from the Animal Resource Branch, DRR, National Institutes of Health. The authors wish to thank Doctor Daniel H. Ringler for valuable suggestions, Mr. Craig J. Biddle and Mr. William Bruden for the preparation of photographs, Ms. Francine Hale for staining of skeletons, and Maggie Meston for secretarial help.

\section{LITERATURE CITED}

Bruce, N.W. 1972 Effects of temporary uterine ischemia on the rat embryo at different maternal abdominal temperatures. J. Reprod. Fertil., 30: 63-69.

- 1976 The effect of ligating a uterine artery on fetal and placental development in the rat. Biol. Reprod. 14: 246.

Cockroft, D. L., and D. A. T. New 1975 Effects of hyperther mia on rat embryos in culture. Nature, 258: 604-606.
Collins, K. J., and J. S. Weiner 1968 Endocrinological aspects of exposure to high environmental temperature. Physiol. Rev., 48: 785 .

Csapo, A. I., and W. G. Wiest 1973 Plasma steroid levels and ovariectomy-induced placental hypertrophy in rats. Endocrinology, 93: 1173-1177.

Edwards, M. J. 1968 Congenital malformations in the rat following induced hyperthermia during gestation. Teratology, 1: 173-177.

- 1969 Congenital defects in guinea pigs: prenatal retardation of brain growth of guinea pigs following hyperthermia during gestation. Teratology, 2: 329-336.

- 1972 Influenza, hyperthermia and congenital malformation. Lancet, 1: 320 .

Edwards, M. J., R. Mulley, S. Ring and R. A. Wanner 1974 Mitotic cell death and delay of mitotic activity in guinea pig embryos following brief maternal hyperthermia. J. Embryol. Exp. Morph., 32: 593-602.

Geber, W. F. 1962 Maternal influences on the fetal car diovascular system in the sheep, dog, rabbit. Amer. J. Physiol., 202: 653-660.

Hainsworth, F. R. 1968 Evaporative water loss from rats in the heat. Amer. J. Physiol., 214: 979-982.

Hasegawa, H. 1955 Effect of thermal shock on the nucleic acids in toad embryos during early stage of development. Nature, 175: 1031 .

Hendrickx, A. G., and G. W. Stone 1976 Preliminary studies on the embryotoxicity of hyperthermia in the bonnet monkey (Macaca radiata). Teratology, 13: 24, abstract.

Kilham, L., and V. H. Ferm 1976 Exencephaly in fetal hamsters following exposure to hyperthermia. Teratology, 14 : 323-326.

Lecyk, M. 1969 The effect of abnormal temperatures applied during the pregnancy on the structure of the vertebral column in the offspring of mammals, showed by the example white mouse. Part II. Hyperthermia. Zoologica Poloniae, 19: 97-114.

Lewin, R. 1973 Does heat harm the fetus? World Medicine, $8: 45-48$.

Lund, D. E. 1969 Gross morphological and chromosomal observations of 4 day rabbit embryos following incubation at elevated temperatures during the first cleavage division. Trans. Kansas Acad. Sci., 72: 230-236.

Morishima, H. O., B. Glaser, W. H. Niemann and L. S. James 1975 Increased uterine activity and fetal deterioration during maternal hyperthermia. Amer. J. Obstet Gynecol., 121: 531-538.

Myers, R. E., A. B. Holt, R. E. Scott, E. D. Mellits and D. B Cheek 1971 Fetal growth retardation produced by ex perimental placental insufficiencies in the rhesus mon. key. Biol. Neonate., 18: 379-394.

Nelsen, N. L., and H. H. Srebnik 1970 Comparison of the reproductive performance of rats at high altitude $(3800 \mathrm{~m})$ and at sea level. Int. J. Biometeorol., 14: 187

Nielsen, N. O. 1969 Teratogenic effects of hyperthermia. In: Teratology, A. Bertelli and L. Donati, eds. Amsterdam Excerpta Medica.

Poswillo, D., H. Nunnerley, D. Sopher and J. Keith 1974 Hyperthermia as a teratogenic agent. Ann. Roy. Coll Surg., 55: 171-174.

Skreb, N., and Z. Frank 1963 Developmental abnormalities in the rat induced by heat-shock. J. Embryol. Exp. Morph., 5: 311-323. 